\title{
Evaluation of minimal fracture liaison service resource: costs and survival in secondary fracture prevention-a prospective one-year study in South-Finland
}

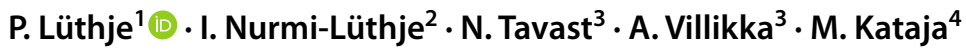

Received: 16 December 2020 / Accepted: 27 February 2021 / Published online: 3 April 2021

(c) The Author(s) 2021

\begin{abstract}
Background Fracture liaison service (FLS) is a secondary prevention model for identification of patients at risk for fragility fractures.

Aims This study was conducted to evaluate the number and costs of secondary prevention of low-energy fractures in the city of Kouvola in Finland.

Methods Women aged $\geq 45$ years and men $\geq 60$ years treated in the emergency department with a low-energy fracture were identified. Laboratory testing, BMI, and DXA scans were performed. Fracture Risk Assessment Tool was used. The direct FLS costs were calculated. Survival was analyzed using univariate and multivariate analysis and the life-table method.

Results 525 patients with 570 fractures were identified. The mean age of women was 73.8 years and of men 75.9 years. Most patients sustained wrist (31\%), hip (21\%) or proximal humerus (12\%) fractures. $41.5 \%$ of the patients had osteoporosis according to DXA scans. $62 \%$ of patients used calcium and vitamin D daily and 38\% started anti-osteoporotic medication. Protective factors for survival were: age $<80$ years, female sex, and S-25OHD concentration of 50-119 nmol/L. Excess mortality was highest among patients with a fracture of the femur. The total annual direct costs of FLS were $1.3 \%$ of the costs of all fractures.

Discussion Many low-energy fracture types were associated with excess mortality. The use of anti-osteoporotic medication was not optimal.

Conclusions FLS increased the catchment of low-energy fracture patients and was inexpensive. However, identification, evaluation and post-fracture assessment of patients should be expedited. Rehabilitation of hip fracture patients needs to be improved.
\end{abstract}

Keywords One-year cohort $\cdot$ Low-energy fractures $\cdot$ Prospective study $\cdot$ Secondary prevention $\cdot$ Direct costs $\cdot$ Survival

\section{Introduction}

Osteoporosis is the most common disease of bone, characterized by reduced mineral density (BMD) and low bone strength, and leading to increased low-energy fracture

\section{P. Lüthje}

peter.luthje@pp.inet.fi

1 North-Kymi Hospital, Liljequistintie 13 B Kuusankoski, 45700 Kouvola, Finland

2 Department of Public Health, University of Helsinki, Helsinki, Finland

3 Kouvola Health Center, Kouvola, Finland

4 National Institute for Health and Welfare, Helsinki, Finland risk. One-third of women and $20 \%$ of men over the age of 50 years will be affected by osteoporotic fracture in their lifetimes [1]. The prevalence of osteoporosis increases with age. Osteoporotic fractures are a remarkable public health problem due to the associated high morbidity and mortality [2].

The most common osteoporotic fracture is a wrist fracture. However, the most serious osteoporotic fracture is a hip fracture requiring surgical treatment. Hip fractures are associated with significant mortality at 30 days $(7-8 \%)[3,4]$ and at 1 year (14-39.5\%) [5-8]. Patients with a hip fracture have a twofold risk of suffering a second hip fracture and their subsequent mortality is increased [9].

Vertebral fracture also is a major predictor of future fracture risk, up to fivefold for subsequent vertebral fracture and 
two- to threefold for fractures at other sites. It also leads to increased mortality [10].

There is a strong evidence indicating that early identification and treatment of osteoporosis are important factors in preventing subsequent fractures in the elderly [11, 12]. Secondary fracture prevention is important in improving the quality of life of aged people. Many studies have shown that fracture liaison services (FLS) has proved to be effective in reducing the frequency of subsequent fractures, in improving adherence to long-term anti-osteoporotic treatment, in decreasing morbidity of these patients and in providing cost savings [13-17].

Our aim was to explore the number of patients with lowenergy fractures, to investigate secondary prevention among them, and to analyze the four-year survival of these patients, treated in North Kymi Hospital in the city of Kouvola, Finland in 2015. Moreover, we evaluated the direct costs of secondary prevention for the organization in charge. Thus far, no similar study has been published in Finland.

\section{Patients and methods}

\section{Study design and population}

We report the data and treatment of all low-energy fractures in women aged $\geq 45$ years and men aged $\geq 60$ years, according to the age limits of FLS programs at the time, treated in an in-patient unit or out-patient unit in North Kymi Hospital in 2015. Also, younger patients who had previous low-energy fractures before the index fracture were taken into account. The hospital is located in the city of Kouvola (86,000 inhabitants) in southeastern Finland $\left(61^{\circ} \mathrm{N}\right)$.

Data were collected in the North Kymi Hospital Emergency Department (level II trauma center). The dedicated coordinating nurse identified the patients from the electronic patient records based on the hospital ICD-10 codes. Data included patients' episodes based on the ICD-10 code, indicating typical osteoporotic fractures: proximal humerus, thoracolumbar spine, pelvis, hip, rib, and ankle as the primary diagnosis. Also, fractures of other locations in upper and lower extremities were included. The study period was from 1 January to 31 December 2015. Every 2 weeks the FLS-coordinator nurse received a list of all fracture patients (women aged $\geq 45$ years and men $\geq 60$ years), wherefrom she verified all low-energy fracture patients. Patients with highenergy fractures or pathological fractures were excluded.

\section{Fracture liaison service}

Our FLS program was a nurse practitioner-led program. The FLS coordinator worked together with an orthopedic surgeon and traumatologist (PL). The screening service of the FLS coordinator nurse took about $70 \%$ of her full-time work, and the physician (PL) worked on a part-time basis. The other four FLS nurses worked on a part-time basis in local health centers and their patients were treated by local physicians. The coordinator nurse identified the patients and sent them a questionnaire on clinical risk factors.

Regarding in-patients who needed longer rehabilitation in health care, for example hip fracture patients or patients with a clinical vertebral fracture, the decision to prescribe anti-osteoporotic medication was made mainly by local physicians working in the rehabilitation department of the Kouvola Health Center, or in some cases by the orthopedic surgeon (PL). In all other cases the orthopedic surgeon (PL) prescribed anti-osteoporotic medication to the patients.

\section{Definition of variables}

Patients were asked to give the following information: sex; age; date of injury; injury mechanism; and previous fractures. If they had sustained previous fractures, the type of fracture was inquired. Previous fractures were also obtained and confirmed from the electronic patient database established in 2004. Moreover, patients were asked questions about risk factors: parental history of hip fracture; familial history of osteoporosis; corticosteroid use; smoking; rheumatoid arthritis or connective tissue diseases; current use of medication including previous anti-osteoporotic medication; start time of anti-osteoporotic medication (date) and name of the medication; use of alcohol $\geq$ three drinks/day; previous DXA (dual-energy X-ray absorptiometry) examination and result; weight and height; and use of vitamin D or calcium or both supplements. According to Finnish guidelines [18], all patients gave samples that were laboratory tested to obtain the following information: sedimentation rate (SR); blood count; alkaline phosphatase (ALP); ionized calcium; creatinine; serum 25-hydroxyvitamin D (S-25OHD); transglutaminase antibodies; thyroid-stimulating hormone (TSH); and testosterone in men. Vitamin D deficiency was defined as a serum $25 \mathrm{OHD}$ concentration of $<50 \mathrm{nmol} / \mathrm{L}$ and optimal concentration for prevention of osteoporosis is $75-120 \mathrm{nmol} / \mathrm{L}$ [18].

\section{Fracture Risk Assessment Tool (FRAX)}

Both the Finnish guidelines [18] and the Finnish practice [19] recommend that the 10-year fracture risk should be estimated using the proprietary Fracture Risk Assessment Tool to screen potential osteoporosis for testing bone mineral density. Additional risk factors such as frequent falls or frequent fractures, not represented in FRAX, require individual clinical judgment. 
According to FRAX, fractures occurring at the spine, hip, distal forearm, and proximal humerus are considered major osteoporotic fractures (MOF). Therefore, the fractures were classified into two groups: (1) MOF and (2) other fractures.

An elevated 10-year probability score was defined as 3\% or more for hip fracture and $20 \%$ or more for MOF.

\section{Bone mineral density (BMD)}

BMD measurements were performed at the lumbar spine (L1-L4), total hip, and femoral neck by DXA using a Lunar densitometer (Prodigy, GE Medical Systems).

According to the WHO criteria, patients were classified based on the lowest T-score in the vertebrae L1-L4, total hip, and femoral neck. T-scores of $\leq-2.5$ standard deviations (SD) below the reference mean were classified as osteoporosis; T-scores between $<-1.0$ and $-2.5 \mathrm{SD}$ were classified as osteopenia; and T-scores $\geq-1.0 \mathrm{SD}$ were classified as normal.

According to Finnish national guidelines, hip fracture patients should be treated with anti-osteoporotic medication without BMD measurements if cancer or other reasons for secondary osteoporosis are excluded [18]. Anti-osteoporotic treatment is generally recommended for patients who have the bone mineral density T-score of -2.5 or less, or a history of spine or hip fracture. According to the Finnish Current Hip Fracture Care Guidelines, anti-osteoporotic treatment should only be considered if the patient would rehabilitate to independent mobility [20].

\section{Costs of FLS services}

The immediate direct FLS costs for each patient were calculated using the cost of DXA scans in 2015; the cost of laboratory tests in 2015; the salaries for an FLS coordinator nurse working on a 70\% basis in FLS; for other FLS nurses; and for a physician working on a part-time basis (about five hours every second or third week in 2015). Because the contributions of the other four FLS nurses were minor (30\%), we used $100 \%$ of the annual salary for the FLS coordinator nurse. The DXA scan service was contracted from the private sector because North Kymi Hospital did not have a bone densitometer. The costs for all examinations of secondary fracture prevention were free of charge for the patient.

\section{Statistical analyses}

Differences in the mean values between the groups were tested with t-test and two-way analysis of variance (ANOVA). For differences between two groups, the chisquared $\left(\chi^{2}\right)$ test, the Fisher's exact test or the Wilcoxon rank-test were used. The $p$ values $<0.05$ were considered statistically significant.

\section{Survival}

Cumulative mortality figures were counted by sex and fracture type at 1,2,3, and 4 post-fracture years. Four-year survival was analyzed using both the Bayesian multivariate model [21] and the life-table method [22]. In the univariate analysis, the odds ratios of survival were calculated for each class of variables and compared with each other within the variable. Statistical dependency within each variable was analyzed using the Chi-squared $\left(\chi^{2}\right)$ test or the Wilcoxon rank test.

Multivariate analysis was performed using an optimizing step-wise procedure based on the Bayesian approach [21]. The optimizing procedure was developed mainly for categorized variables and it does not require a perfect variable matrix. The procedure selects, using a heuristic approach, the combination of variables that best explains the selected outcome variable. The Bayesian approach is applied by counting posterior probability ratios for each combination.

The aim was to find an optimal combination of variables that provides a better explanation than all the variables together. The relationship between the true positives and true negatives was graphically described as a receiver operating characteristic curve (ROC), for which the area under the curve (AUC) describes the approximate explanatory power of the model.

\section{Relative survival}

Survival in relation to the reference population was analyzed according to sex and type of fracture using the life-table method [22]. In this method, the observed survival rates of the groups are compared with the survival rates based on sex- and age-specific life tables for the whole population of the same age and time period in Finland. The calculation of the survival of the reference population is 1.00 . Thus, if the survival curve of the group remains below the survival of the reference population, there is an excess mortality in the group. Analysis of deaths was conducted based on information obtained from the nationwide administrative register, the Cause of Death Register of Statistics Finland.

The follow-up period started on 1 January 2015, and the closing date was 15 April 2020. The deaths were obtained from the Finnish Cause of Death Register. The follow-up time of survival was from 1 January 2015 to 15 April 2020 (63.5 months $=5.3$ years). All patients were followed for a minimum of 51 months (4.3 years).

\section{Results}

A total of 525 white native Finns (406 women and 119 men) with 570 low-energy fractures (see supplementary Fig. 1) were identified by the FLS nurses ( $70 \%$ by the FLS 
coordinator nurse and a total of $30 \%$ by four other FLS nurses). The mean age of women was 73.8 years (SD 12) and of men 75.9 years (SD 11) (n.s.) (Table 1). The median age in women was 50.5 years (38-98 years) and in men 54.1 years (43-97 years) (n.s.).

Twenty-two patients (22/525) sustained two fractures in the same accident. In addition, 23/525 patients had two or three different falling accidents at different times. Therefore, the total number of cases was 548 (Fig. 1 and Table 1). These cases were mainly women $(n=20)$ and their mean age was higher than that of women with only one accident
(80.4 years, SD 12.8 vs. 73.8 years, SD 12.0, respectively, $t=2.089, p<0.05$ ).

The distribution of the different fracture types according to sex is shown in Table 1. Women sustained more fractures than men. Every third woman and every seventh man sustained a wrist fracture $\left(\chi^{2}=20.26\right.$, d.f. $\left.=1, p<0.001\right)$. One in three men and one in five women sustained a hip fracture $\left(\chi^{2}=16.53\right.$, d.f. $\left.=1, p<0.001\right)$. The rate of MOF in women was 73.5\% (313/426) and in men 73.0\% (89/122).

Over half of the patients (54\%) were treated as in-patient and $43 \%$ of the patients needed operative treatment. The

Table 1 Number of low-energy fractures among 525 patients and the mean ages according to previous fractures, side of index fractures and type of treatment

\begin{tabular}{|c|c|c|c|c|c|c|c|}
\hline & \multicolumn{2}{|c|}{ Women $(n=406)$} & \multicolumn{2}{|c|}{ Men $(n=119)$} & \multicolumn{2}{|c|}{ Total $(n=525)$} & \multirow[t]{2}{*}{ Statistic } \\
\hline & $n(\%)$ & Mean age (SD) & $n(\%)$ & Mean age (SD) & $n(\%)$ & Mean age (SD) & \\
\hline $\begin{array}{l}\text { Number and age of } \\
\text { patients }\end{array}$ & $406(77.3)$ & $73.8(12.0)$ & $119(22.7)$ & $75.9(11.0)$ & $525(100)$ & $74.3(11.8)$ & n.s \\
\hline \multicolumn{8}{|l|}{$\begin{array}{l}\text { Previous fractures } \\
(n=418 / 525)\end{array}$} \\
\hline Yes & $157(48.8)$ & $75.6(11.7)$ & $33(36.5)$ & $75.3(12.3)$ & $192(45.9)$ & $75.5(11.7)$ & \\
\hline No & $165(51.2)$ & $71.3(11.7)$ & $61(63.5)$ & $75.8(10.8)$ & $226(54.1)$ & $72.5(11.6)$ & \multirow{2}{*}{$\begin{array}{l}F \text {-test } 6.90, \text { df } 1 ; 413 \text {, } \\
p<0.01^{\mathrm{b}}\end{array}$} \\
\hline Total & $322(100)$ & $73.3(11.9)$ & $96(100)$ & $75.6(11.3)$ & $418(100)$ & $73.9(11.8)$ & \\
\hline \multicolumn{8}{|l|}{$\begin{array}{l}\text { Site of index fracture } \\
\quad(n=525)\end{array}$} \\
\hline Proximal humerus & $50(12.3)$ & $75.0(11.2)$ & $15(12.6)$ & $74.7(12.3)$ & $65(12.4)$ & $74.9(11.3)$ & \\
\hline Other part of humerus & $9(2.2)$ & $72.2(7.8)$ & $4(3.4)$ & $63.8(1.9)$ & $13(2.5)$ & $69.6(7.6)$ & \\
\hline Wrist & $135(33.3)$ & $69.9(11.0)$ & $15(12.6)$ & $74.7(7.2)$ & $150(28.6)$ & $70.4(10.8)$ & \\
\hline Other part of forearm & $17(4.2)$ & $70.6(15.2)$ & $3(2.5)$ & $64.9(7.1)$ & $20(3.8)$ & $69.7(14.3)$ & \\
\hline Vertebra & $28(6.9)$ & $74.6(11.2)$ & $15(12.6)$ & $80.8(11.3)$ & $43(8.2)$ & $76.8(11.5)$ & \\
\hline Rib & $11(2.7)$ & $82.2(8.7)$ & $7(5.9)$ & $67.0(13.2)$ & $18(3.4)$ & $76.3(12.8)$ & \\
\hline Pelvis & $10(2.5)$ & $83.2(5.6)$ & $1(0.8)$ & 79.4 & $11(2.1)$ & $82.9(5.4)$ & \\
\hline Hip & $72(17.7)$ & $81.6(10.6)$ & $41(34.5)$ & $79.7(10.2)$ & $113(21.5)$ & $80.9(10.5)$ & \\
\hline Other part of femur & $9(2.2)$ & $83.4(8.3)$ & $4(3.4)$ & $78.8(11.7)$ & $13(2.5)$ & $82.0(9.2)$ & \\
\hline Tibia & $19(4.7)$ & $70.5(12.4)$ & $4(3.4)$ & $76.2(9.0)$ & $23(4.4)$ & $71.5(11.9)$ & \multirow{4}{*}{$\begin{array}{l}F \text {-test } 9.72, \text { df } 11 ; 510, \\
p<0.001^{\mathrm{b}} \\
\chi^{2}=31.02, \mathrm{df}=11, \\
p<0.01\end{array}$} \\
\hline Ankle & $44(10.8)$ & $67.5(10.8)$ & $9(7.6)$ & $69.8(7.5)$ & $53(10.1)$ & $67.9(10.3)$ & \\
\hline Other fracture & $2(0.5)$ & $82.7(0.7)$ & $1(0.8)$ & 59.7 & $3(0.6)$ & $75.0(13.3)$ & \\
\hline Total & $406(100)$ & $73.8(12.0)$ & $119(100)$ & $75.9(11.0)$ & $525(100)$ & $74.3(11.8)$ & \\
\hline \multicolumn{8}{|l|}{ Treatment $(n=548)^{\mathrm{a}}$} \\
\hline Conservative & $249(58.5)$ & $73.2(11.6)$ & $65(53.3)$ & $74.6(11.0)$ & $314(57.3)$ & $73.5(11.5)$ & \\
\hline Operative & $177(41.5)$ & $74.5(12.6)$ & $57(46.7)$ & $77.3(10.8)$ & $234(42.7)$ & $75.2(12.3)$ & \\
\hline Total & $426(100)$ & $73.8(12.0)$ & $122(100)$ & $75.9(11.0)$ & $548(100)$ & $74.2(11.8)$ & n.s \\
\hline \multicolumn{8}{|l|}{$\begin{array}{l}\text { Inpatient treatment } \\
\qquad(n=548)^{\mathrm{a}}\end{array}$} \\
\hline Yes & $218(51.2)$ & $76.8(12.4)$ & $76(62.2)$ & $78.5(10.6)$ & $294(53.5)$ & $77.2(12.1)$ & \\
\hline No & $208(48.8)$ & $71.2(11.0)$ & $46(37.8)$ & $71.6(9.8)$ & $254(46.5)$ & $71.3(10.8)$ & \multirow{2}{*}{$\begin{array}{l}F \text {-test } 36.87 \text {, df } 1 ; 542, \\
p<0.001^{\mathrm{b}}\end{array}$} \\
\hline Total & $426(100)$ & $74.1(12.1)$ & $122(100)$ & $75.9(10.9)$ & $548(100)$ & 74.5 (11.9) & \\
\hline
\end{tabular}

${ }^{\mathrm{a}} 23 / 525$ patients had two or three accidents at different times, the total number of cases was 548 (426 women and 122 men)

${ }^{b}$ Vertical ANOVA

mean age of patients by fracture type according to sex is 
Fig. 1 Survival of patients $(n=525)$ according to sex

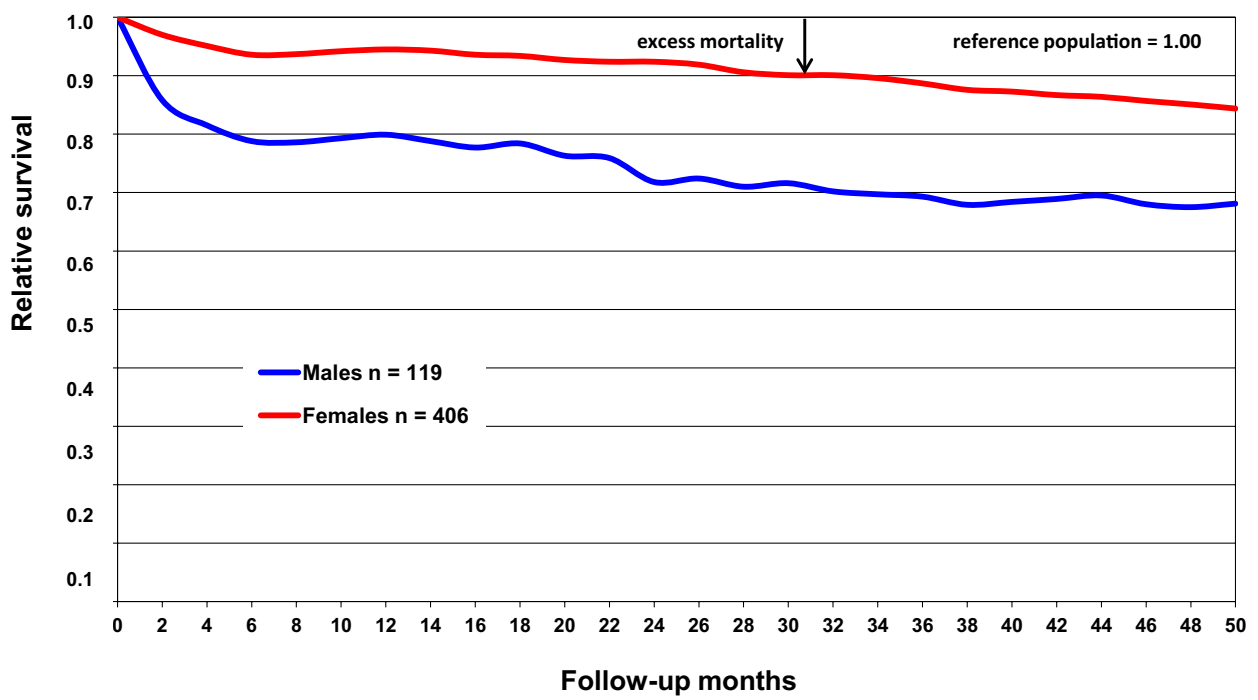

shown in Table 1. In-patients were older than others, and patients with a fracture of the pelvis, hip or other part of the femur were older than those with other fractures (Table 1).

\section{Clinical risk factors}

Previous fractures were the most common $(46 \%)$ clinical risk factors reported by our patients in 2015 (Table 1), followed by current smoking (16.4\%) (Table 2). All other clinical risk factors used in the FRAX algorithms were reported by $11.4 \%$ or less of these adults (Table 2). Patients with previous fractures were older than those without previous fractures (Table 1).

Among hip fracture patients, 35\% (40/113) had sustained a total of 74 previous fractures. Three out of $113 \mathrm{hip}$ fracture patients sustained a second hip fracture of the contralateral hip.

Of the patients who returned the questionnaire, and according to the electronic medical records, 46\% (192/418) had sustained a total of 287 previous fractures: 123 patients had one, 51 patients had two, 12 patients had three, four patients had four, and two patients had sustained five previous fractures.

\section{Abnormal laboratory results}

There were 20 patients $(3.8 \%, 20 / 525)$ with abnormal laboratory results who were referred to an internist. In eight cases the reason was elevated calcium and parathormone (PTH) result, in four cases elevated ALP result, in two cases elevated anti-transglutaminase antibodies, and in six cases the reason was many previous fractures. In two cases the patient had a celiac disease, in one case primary sclerosing cholangitis and in one case parathyroid adenoma which was treated operatively. The rest 16 patients remained in the follow-up of the internist. None of the male patients had too low testosterone levels, which would require testosterone treatment. There was no secondary osteoporosis among the six patients with several previous fractures.

\section{Vitamin D, BMI and BMD}

The S-25OHD concentration was measured in 368 patients (70\%). In half of these patients $(178 / 368,48 \%)$, the S-25OHD level was optimal (75-120 nmol/L) (Table 2). The mean S-25OHD concentration was $93.4 \mathrm{nmol} / \mathrm{L}$ (SD 36.1). Among 113 hip fracture patients, the mean S-25OHD concentration was $94.5 \mathrm{nmol} / \mathrm{L}$ (SD 34.7).

The body mass index $(\mathrm{BMI})\left(\mathrm{kg} / \mathrm{m}^{2}\right)$ could be calculated in 324 patients (62\%). BMI was normal in $41 \%$ $\left(18.5-25.0 \mathrm{~kg} / \mathrm{m}^{2}\right)$ of these patients (Table 2). The mean value was $26.3 \mathrm{~kg} / \mathrm{m}^{2}$, almost equal in both sexes. The mean BMI value was lowest among hip fracture patients and highest among vertebral fracture patients $(p<0.01)$.

The questionnaire was returned by 374 patients $(71 \%)$, of whom in 66\% (246/374) had their BMD measured. In 34\% (128/374), the measure was not necessary due to fracture type, scarce risk-scores, or age. Of all the BMD-measured patients, $41.5 \%$ (102/246) (82 women and 20 men) had osteoporosis, and 52.8\% (130/246) (112 women and 18 men) had osteopenia. In 14 patients (5.7\%), the BMD result was normal.

\section{FRAX}

The FRAX tool was in use in $62 \%(323 / 525)$ of cases. Approximately $67 \%$ of women (176/261) and $63 \%$ of men (39/62) had a hip fracture probability that was $3 \%$ or more. 
Table 2 Anti-osteoporotic medication prior to index fracture, clinical risk factors, vitamin D level, BMI, calcium plus vitamin D use and antiosteoporotic medication after index fracture

\begin{tabular}{|c|c|c|c|c|}
\hline & Women $(\%)$ & $\operatorname{Men}(\%)$ & Total $(\%)$ & $p$ \\
\hline \multicolumn{5}{|c|}{ Anti-osteoporotic medication prior to index fracture $(n=374 / 525)^{\mathrm{a}}$} \\
\hline Yes & $43(14.4)$ & $11(14.5)$ & $54(14.4)$ & \multirow{3}{*}{ n.s. } \\
\hline No & $255(85.6)$ & 65 (85.5) & $320(85.6)$ & \\
\hline Total & $298(100)$ & $76(100)$ & $374(100)$ & \\
\hline \multicolumn{5}{|c|}{ Parental history of hip fracture $(n=355 / 525)$} \\
\hline Yes & $26(9.2)$ & $4(5.6)$ & $30(8.5)$ & \multirow{3}{*}{ n.s. } \\
\hline No & $258(90.8)$ & $67(94.4)$ & $325(91.5)$ & \\
\hline Total & $284(100)$ & $71(100)$ & $355(100)$ & \\
\hline \multicolumn{5}{|c|}{ Smoking $(n=359 / 525)$} \\
\hline Yes & $38(13.2)$ & $21(29.2)$ & $59(16.4)$ & \multirow{3}{*}{$\begin{array}{l}\chi^{2}=10.63 \text {, d.f. } 1 \\
p<0.01\end{array}$} \\
\hline No & $249(86.8)$ & $51(70.8)$ & $300(83.6)$ & \\
\hline Total & $287(100)$ & $72(100)$ & $359(100)$ & \\
\hline \multicolumn{5}{|c|}{ Arthritis rheumatoides $(n=365 / 525)$} \\
\hline Yes & $28(9.6)$ & $6(8.2)$ & $34(9.3)$ & \multirow{3}{*}{ n.s. } \\
\hline No & $264(90.4)$ & $67(91.8)$ & $331(90.7)$ & \\
\hline Total & $292(100)$ & $73(100)$ & $365(100)$ & \\
\hline \multicolumn{5}{|c|}{ Corticosteroid use $(n=369 / 525)$} \\
\hline Yes & $37(12.5)$ & $5(6.8)$ & $42(11.4)$ & \multirow{3}{*}{ n.s. } \\
\hline No & $258(87.5)$ & $69(93.2)$ & $327(88.6)$ & \\
\hline Total & $295(100)$ & $74(100)$ & $369(100)$ & \\
\hline \multicolumn{5}{|c|}{ Alcohol use ( $\geq 3$ drinks/day; $n=357 / 525$ ) } \\
\hline Yes & $8(2.8)$ & $12(16.9)$ & $20(5.6)$ & \multirow{3}{*}{$\begin{array}{l}\chi^{2}=21.40, \text { d.f } 1, \\
p<0.0001\end{array}$} \\
\hline No & $278(97.2)$ & $59(83.1)$ & $337(94.4)$ & \\
\hline Total & $286(100)$ & $71(100)$ & $357(100)$ & \\
\hline \multicolumn{5}{|c|}{ Vitamin D level in $\mathrm{nmol} / \mathrm{L}(n=368 / 525)$} \\
\hline-24 & $4(1.4)$ & $0(0)$ & $4(1.1)$ & \multirow{7}{*}{ n.s. } \\
\hline $25-49$ & $19(6.4)$ & $6(8.3)$ & $25(6.8)$ & \\
\hline $50-74$ & $63(21.3)$ & $23(31.9)$ & $86(23.5)$ & \\
\hline $75-120$ & $150(50.7)$ & $28(38.9)$ & $178(48.4)$ & \\
\hline $121-150$ & 47 (15.9) & $9(12.5)$ & $56(15.0)$ & \\
\hline $151-$ & $13(4.4)$ & $6(8.3)$ & $19(5.2)$ & \\
\hline Total & $296(100)$ & $72(100)$ & $368(100)$ & \\
\hline \multicolumn{5}{|c|}{$\operatorname{BMI}\left(\mathrm{kg} / \mathrm{m}^{2}\right)(n=324 / 525)$} \\
\hline$<18.5$ & $7(2.7)$ & $3(4.8)$ & $10(3.1)$ & \\
\hline $18.5-20.5$ & $15(5.7)$ & $4(6.5)$ & $19(5.9)$ & \\
\hline $20.6-25.0$ & $92(35.1)$ & $22(35.4)$ & $114(35.2)$ & \\
\hline $25.01-30.0$ & $90(34.4)$ & $24(38.7)$ & $114(35.2)$ & \\
\hline $30.01-35.0$ & $44(16.8)$ & $5(8.1)$ & $49(15.1)$ & \multirow{3}{*}{ n.s. } \\
\hline $35.01-$ & $14(5.3)$ & $4(6.5)$ & $18(5.5)$ & \\
\hline Total & $262(100)$ & $62(100)$ & $324(100)$ & \\
\hline \multicolumn{5}{|c|}{ Calcium and vitamin D use after index fracture $(n=525)$} \\
\hline Yes & $269(66.3)$ & $57(47.9)$ & $326(62.1)$ & \multirow{4}{*}{$\begin{array}{l}\chi^{2}=13.27, \text { d.f. } 2 \\
p<0.01\end{array}$} \\
\hline No information & $117(28.8)$ & $52(43.7)$ & $169(32.2)$ & \\
\hline No & $20(4.9)$ & $10(8.4)$ & $30(5.7)$ & \\
\hline Total & $406(100)$ & $119(100)$ & $525(100)$ & \\
\hline \multicolumn{5}{|c|}{ Anti-osteoporotic treatment after index fracture $(n=386 / 525)$} \\
\hline Yes & $120(38.8)$ & $26(33.8))$ & $146(37.8)$ & \\
\hline No & $155(50.2)$ & $41(53.2)$ & $196(50.8)$ & \\
\hline Not accepted & $18(5.8)$ & $6(7.8)$ & $24(6.2)$ & \\
\hline
\end{tabular}


Table 2 (continued)

\begin{tabular}{|c|c|c|c|c|}
\hline & Women $(\%)$ & Men $(\%)$ & Total $(\%)$ & $p$ \\
\hline No information & $16(5.2)$ & $4(5.2)$ & $20(5.2)$ & n.s. \\
\hline Total & $309(100)$ & $77(100)$ & $386(100)$ & \\
\hline \multicolumn{5}{|c|}{$\begin{array}{l}\text { Anti-osteoporotic treatment among MOF patients who were alive } \\
12 \text { months after the index fracture }\end{array}$} \\
\hline Hip (women: $\mathrm{n}=56$; men: $n=22$ ) & $28(50.0)$ & $9(40.9)$ & $37 / 78(47.4)$ & \\
\hline Vertebra (women: $n=27$; men: $n=11$ ) & $18(66.7)$ & $6(54.5)$ & $24 / 38(63.2)$ & \\
\hline Proximal humerus (women: $n=49$; men: $n=13$ ) & $20(40.8)$ & $2(15.4)$ & $22 / 62(35.5)$ & \\
\hline Wrist (women: $n=131$; men: $n=13$ ) & $29(22.1)$ & $5(38.5)$ & $34 / 144(23.6)$ & n.s. \\
\hline Total (women: $263 ;$ men $=59$ ) & $95(36.1)$ & $22(37.3)$ & $117 / 321(36.4)$ & \\
\hline
\end{tabular}

MOF major osteoporotic fracture

${ }^{a}$ The questionnaire was returned by 374/525 patients. The differences in figures in Table 2 were due to missing information in the questionnaires. In some cases missing information was found in patients' medical records

About $27 \%$ of the patients $[87 / 323 ; 33 \%$ in women $(86 / 261)$; $1 / 62(1.6 \%)$ in men] had a MOF probability that was $20 \%$ or more.

\section{Use of calcium plus vitamin D}

Of all patients, $62 \%$ used calcium plus vitamin D supplements (Table 2) at a minimum dose of 800 IU vitamin D per day. Calcium plus vitamin D was used by $47 \%$ of hip fracture patients, $76 \%$ of vertebral fracture patients, $68 \%$ of wrist fracture patients and $66 \%$ of proximal humerus fracture patients. Daily calcium supplementation was recommended if the patient was unable to achieve an intake of $1200 \mathrm{mg} /$ day of calcium from food sources.

\section{Anti-osteoporotic treatment}

According to the questionnaire, $14 \%$ of patients used antiosteoporotic medication prior to the index fracture, mostly bisphosphonates (86\%) (Table 2). Post-fracture anti-osteoporotic medication was started on average 200 days after the index fracture in $38 \%$ of the patients (Table 2). Before starting the anti-osteoporotic treatment (bisphosphonates or denosumab), patients were recommended for dental examination for possible periodontal diseases. An antiresorptive medication was started after the dentist's approval.

The total use of anti-osteoporotic medication, and among MOF patients who were alive 12 months after the index fracture, is shown in Table 2. Overall, $36 \%$ of the MOF patients still used anti-osteoporotic medication at 1 year after the fracture.

In most cases, subcutaneous denosumab (60 mg every 6 months) (47.5\%) was used followed by oral bisphosphonates $(38 \%$ ) (alendronate $70 \mathrm{mg}$ or risedronate $35 \mathrm{mg}$ once a week), intravenous zoledronic acid $5 \mathrm{mg}$ (13.5\%), oral strontium ranelate $2 \mathrm{~g} /$ day ( $1 \%$ ), and subcutaneous teriparatide $20 \mu \mathrm{g} /$ day $(1 \%)$.

The primary drug option for patients with hip fracture was intravenous zoledronic acid ( $5 \mathrm{mg}$ per year, three times) to avoid compliance problems, and it was free of charge for the patient. Half of the hip fracture patients started with intravenous zoledronic acid, $41 \%$ with subcutaneous denosumab, and $8 \%$ with oral bisphosphonates.

\section{Costs in 2015}

The annual salary of the FLS coordinator nurse was $32900 €$ and the salary of the physician (part-time basis) was $5100 €$ (70 €/h). The costs of laboratory tests were $52.23 € /$ patient for women and $73.75 € /$ patient for men. The cost for men was higher than for women due to testing testosterone. The total laboratory costs for 294 women and in 72 men totaled $20666 €$. The cost for one BMD measurement (lumbar spine and hip) was $110 €$. Thus, the total costs for all DXA scans $(n=246)$ totaled $27060 €$. Altogether, the cost for FLS totaled $85726 €$ in the year 2015 .

\section{Mortality}

The mortality of both sexes with different fracture types was studied separately. The highest one-year mortality among males was in those with hip fractures (46\%) and vertebral fractures $(27 \%)$. In females, the highest one-year mortality was among those with femoral shaft or distal femur fracture (44\%) and pelvis fractures (30\%) (Table 3). The four-month and one-year mortality among hip fracture patients were $25 \%$ and $31 \%$, respectively.

At the end of the follow-up (4 years), the highest mortality among males was noticed in those with hip fractures $(68 \%)$ and proximal humerus fractures (53\%). Correspondingly, the highest mortality among females was found in 
those with femoral shaft or distal femur fractures (78\%) and hip fractures (54\%) (Table 3).

In total, $70 \%(365 / 525)$ of the patients survived 4 years after the index fracture (Table 3). Differences in mortality between sexes were found at 4 years. Mortality was higher among men than women in proximal humerus fractures (Fishers exact $p=0.0435$ ) and in hip fractures (Fisher's exact $p=0.0001)$.

\section{Survival}

Univariate analysis included the following variables: sex, age, S-25OHD concentration level, and type of fracture (Table 4).

In the multivariate analysis (Table 5), the most protective factors were: age under 80 years, female sex, and S-25OHD concentration of $50-119 \mathrm{nmol} / \mathrm{L}$. The model correctly predicted $80.2 \%$ of the cases. The sensitivity and specificity of the rule were $79.1 \%$ and $80.7 \%$, respectively (see supplementary Table 1). The $\kappa$ value was 0.58 (95\% CI 0.50-0.65), i.e. moderate. The graphic description of the model (AUC) is shown in supplementary Fig. 2.

In the total data, survival in relation to the reference population was higher among women than men (Fig. 1). There was no significant difference either in the mean age or in the median age between males and females. Survival varied according to the fracture type (Fig. 2). Patients with a fracture of the femoral shaft or distal femur had the lowest rate of survival followed by patients with a hip fracture, pelvis fracture and vertebral fracture, respectively. There was no excess mortality among patients with forearm, wrist or ankle fracture.

\section{Discussion}

Our FLS program indicates the necessity of this service: about $75 \%$ of the patients belonged to the MOF category, nearly half (46\%) of the patients had previous fractures, and more than one out of three $(36 \%)$ of them had two to five previous fractures. Moreover, among hip fracture patients the rate of previous fractures was high (35\%). Nevertheless, according to the questionnaire, only $14 \%$ of our patients used anti-osteoporotic treatment before the index fracture.

The treatment of patients with osteoporotic fractures is expensive. According to a US study, in women aged 55 years and older, the hospitalization burden of these fractures and population facility-related hospital costs were higher than those of either myocardial infarction, stroke, or breast cancer [23]. In our study, the one-year treatment costs of 116 hip fracture patients for the city of Kouvola (86 000 inhabitants) totaled 3.52 million euros in the study year 2015 ( $€ 30$ 338/patient) based on the Finnish PERFECT Hip Fracture Database [24]. According to a study in the European Union, hip fractures were estimated to account for $54 \%$, and other osteoporotic fractures for $46 \%$ of the costs of all osteoporotic fractures in the EU [25]. Based on that estimation, the total costs of all osteoporotic fractures totaled about 6.52 million euros in our study in 2015 for the city of Kouvola. However, the direct

Table 3 Cumulative mortality (at 1, 2, 3 and 4 years) among 525 patients with low energy fractures according to sex and fracture type

\begin{tabular}{|c|c|c|c|c|c|c|c|c|c|c|c|c|c|c|c|c|c|c|}
\hline & \multicolumn{8}{|c|}{ Males $(n=119)^{\mathrm{a}}$} & \multicolumn{8}{|c|}{ Females $(n=406)^{\mathrm{a}}$} & \multirow{2}{*}{\multicolumn{2}{|c|}{$\frac{\text { All }(n=525)^{\mathrm{a}}}{4 \text { year }}$}} \\
\hline & \multicolumn{2}{|c|}{1 year } & \multicolumn{2}{|c|}{2 year } & \multicolumn{2}{|c|}{3 year } & \multicolumn{2}{|c|}{4 year } & \multicolumn{2}{|c|}{1 year } & \multicolumn{2}{|c|}{2 year } & \multicolumn{2}{|c|}{3 year } & \multicolumn{2}{|c|}{4 year } & & \\
\hline & $n$ & $\%$ & $n$ & $\%$ & $n$ & $\%$ & $n$ & $\%$ & $n$ & $\%$ & $n$ & $\%$ & $n$ & $\%$ & $n$ & $\%$ & $n$ & $\%$ \\
\hline Proximal humerus & 2 & 13 & 5 & 33 & 7 & 47 & 8 & 53 & 1 & 2 & 4 & 8 & 7 & 14 & 11 & 22 & 19 & 29 \\
\hline Other part of humerus & 0 & 0 & 1 & 25 & 2 & 50 & 2 & 50 & 1 & 11 & 1 & 11 & 2 & 22 & 2 & 22 & 4 & 31 \\
\hline Wrist & 2 & 13 & 3 & 20 & 3 & 20 & 4 & 27 & 4 & 3 & 8 & 6 & 13 & 7 & 18 & 13 & 22 & 15 \\
\hline Other part of forearm & 0 & 0 & 1 & 33 & 1 & 33 & 1 & 33 & 0 & 0 & 2 & 12 & 2 & 12 & 4 & 24 & 5 & 25 \\
\hline Costa & 0 & 0 & 1 & 14 & 1 & 14 & 1 & 14 & 2 & 18 & 2 & 18 & 3 & 27 & 6 & 54 & 7 & 39 \\
\hline Vertebra & 4 & 27 & 6 & 40 & 7 & 47 & 7 & 47 & 1 & 4 & 4 & 14 & 5 & 18 & & 25 & 14 & 33 \\
\hline Pelvis & 0 & 0 & 0 & 0 & 0 & 0 & 0 & 0 & 3 & 30 & 4 & 40 & 4 & 40 & 5 & 50 & 5 & 45 \\
\hline Hip & 19 & 46 & 23 & 56 & 25 & 61 & 28 & 68 & 16 & 22 & 23 & 32 & 34 & 47 & 39 & 54 & 67 & 59 \\
\hline Other part of femur & 1 & 25 & 1 & 25 & 1 & 25 & 1 & 25 & 4 & 44 & 5 & 56 & 6 & 67 & 7 & 78 & 8 & 62 \\
\hline Tibia & 1 & 25 & 1 & 25 & 1 & 25 & 1 & 25 & 3 & 16 & 3 & 16 & 4 & 21 & & 21 & 5 & 22 \\
\hline Ankle & 0 & 0 & 0 & 0 & 0 & 0 & 0 & 0 & 1 & 2 & 2 & 5 & 3 & 7 & 4 & 9 & 4 & 8 \\
\hline Other fracture & 0 & 0 & 0 & 0 & 0 & 0 & 0 & 0 & 0 & 0 & 0 & 0 & 0 & 0 & 0 & 0 & 0 & 0 \\
\hline Total & 29 & 24 & 42 & 35 & 48 & 40 & 53 & 44 & 36 & 9 & 58 & 14 & 83 & 20 & 107 & 26 & 160 & 30 \\
\hline
\end{tabular}

${ }^{\mathrm{a}}$ Total numbers of the 12 fracture types according to sex are presented in Table 1 
Table 4 Univariate analysis of four variables ${ }^{\mathrm{a}}$ in relation to survival data $(n=525)$

\begin{tabular}{|c|c|c|c|c|c|c|}
\hline Variable & Negative & Positive & Total & OR & $95 \% \mathrm{CI}$ & Statistic \\
\hline \multicolumn{7}{|l|}{ Sex } \\
\hline Male & 62 & 57 & 119 & 2.19 & $1.45-3.31$ & \\
\hline Female & 286 & 120 & 406 & 0.46 & $0.30-0.69$ & $\chi^{2}=13.86, d f=1, p<0.001$ \\
\hline \multicolumn{7}{|l|}{ Age } \\
\hline$<60$ & 61 & 0 & 61 & 0.01 & $0.003-0.06$ & \\
\hline $60-69$ & 112 & 19 & 131 & 0.25 & $0.16-0.71$ & \\
\hline $70-79$ & 117 & 36 & 153 & 0.50 & $0.28-0.85$ & \\
\hline 80-89 & 52 & 84 & 136 & 5.14 & $3.08-9.03$ & \\
\hline$\geq 90$ & 6 & 38 & 44 & 15.58 & $7.75-31.32$ & $\mathrm{Wx}=11.81, p<0.001$ \\
\hline \multicolumn{7}{|c|}{ S-25OHD concentration level ${ }^{\mathrm{b}}$} \\
\hline-49 & 22 & 7 & 29 & 1.12 & $0.46-2.71$ & \\
\hline $50-74$ & 72 & 14 & 86 & 0.61 & $0.33-1.15$ & \\
\hline $75-119$ & 138 & 35 & 173 & 0.80 & $0.49-1.31$ & \\
\hline$\geq 120$ & 54 & 26 & 80 & 2.00 & $1.16-3.44$ & $\mathrm{Wx}=1.886, \mathrm{n} . \mathrm{s}$ \\
\hline \multicolumn{7}{|c|}{ Type of fracture $(n=522)^{\mathrm{c}}$} \\
\hline Pelvis & 6 & 5 & 11 & 1.66 & $0.50-5.44$ & \\
\hline Humerus & 52 & 26 & 78 & 0.98 & $0.61-1.57$ & \\
\hline Wrist & 122 & 28 & 150 & 0.35 & $0.22-0.55$ & \\
\hline Vertebra & 28 & 15 & 43 & 1.06 & $0.56-2.02$ & \\
\hline Hip & 43 & 70 & 113 & 4.64 & $3.05-7.06$ & \\
\hline Ankle & 48 & 5 & 53 & 0.18 & $0.08-0.43$ & \\
\hline Costa & 10 & 8 & 18 & 1.60 & $0.63-4.10$ & \\
\hline Forearm & 14 & 6 & 20 & 0.84 & $0.32-2.21$ & \\
\hline Shaft or distal femur & 5 & 8 & 13 & 3.25 & $1.12-9.52$ & \\
\hline Tibia & 18 & 5 & 23 & 0.53 & $0.20-1.44$ & $\chi^{2}=70.68, d f=9, p<0.001$ \\
\hline
\end{tabular}

$\chi^{2}$ Chi-squared test, $d f$ degrees of freedom, OR odds ratio, n.s. not significant, $S$-25OHD serum hydroxyvitamin D, $W x$ Wilcoxon rank test

${ }^{a}$ All the classes of the variables are compared with each other within the variable

${ }^{\mathrm{b}} n=368$

${ }^{\mathrm{c}}$ Three small bone fractures were omitted

\begin{tabular}{llllll}
\hline RR-limit & $\begin{array}{l}\text { False negative } \\
\text { count }\end{array}$ & Sensitivity & Specificity & $\kappa$ & Added variable \\
\hline 0.51 & 55 & 68.9 & 83.3 & 0.520 & Age $(<80$ years $)$ \\
0.56 & 37 & 79.1 & 77.9 & 0.540 & Sex (female) \\
0.88 & 37 & 80.7 & 0.575 & $\begin{array}{c}\text { S- } 25 \text { OHD concen }- \\
\text { tration }(50-\end{array}$ \\
& 79.1 & & & 119 nmol/L) \\
& 36 & 79.7 & 0.538 & Type of fracture \\
\hline
\end{tabular}

Table 5 The most important factors (in italics) explaining survival selected out of three variables in 525 patients costs for secondary fracture prevention were only $1.3 \%$ ( $€ 85726)$ of the total annual costs.

Subsequent fractures can be prevented if osteoporotic fractures are identified and treated. A recent Swedish national register study showed that in women aged $\geq 50$ years with a fragility fracture at any skeletal location, the incidence of subsequent fractures within 12 months was $7.1 \%$, increasing to $12 \%$ at 24 months [26].
A similar result was found in postmenopausal women in the Netherlands: the absolute risk of any subsequent fracture in the year following the first fracture was 6\% [27]. In a large US study involving women, the incidence of any subsequent fracture was $10 \%$ within 1 year of initial fracture [28].

In the present study, $47 \%$ of all hip fracture patients who survived 12 months after the index fracture used 
Fig. 2 Survival of patients $(n=525)$ according to fracture type

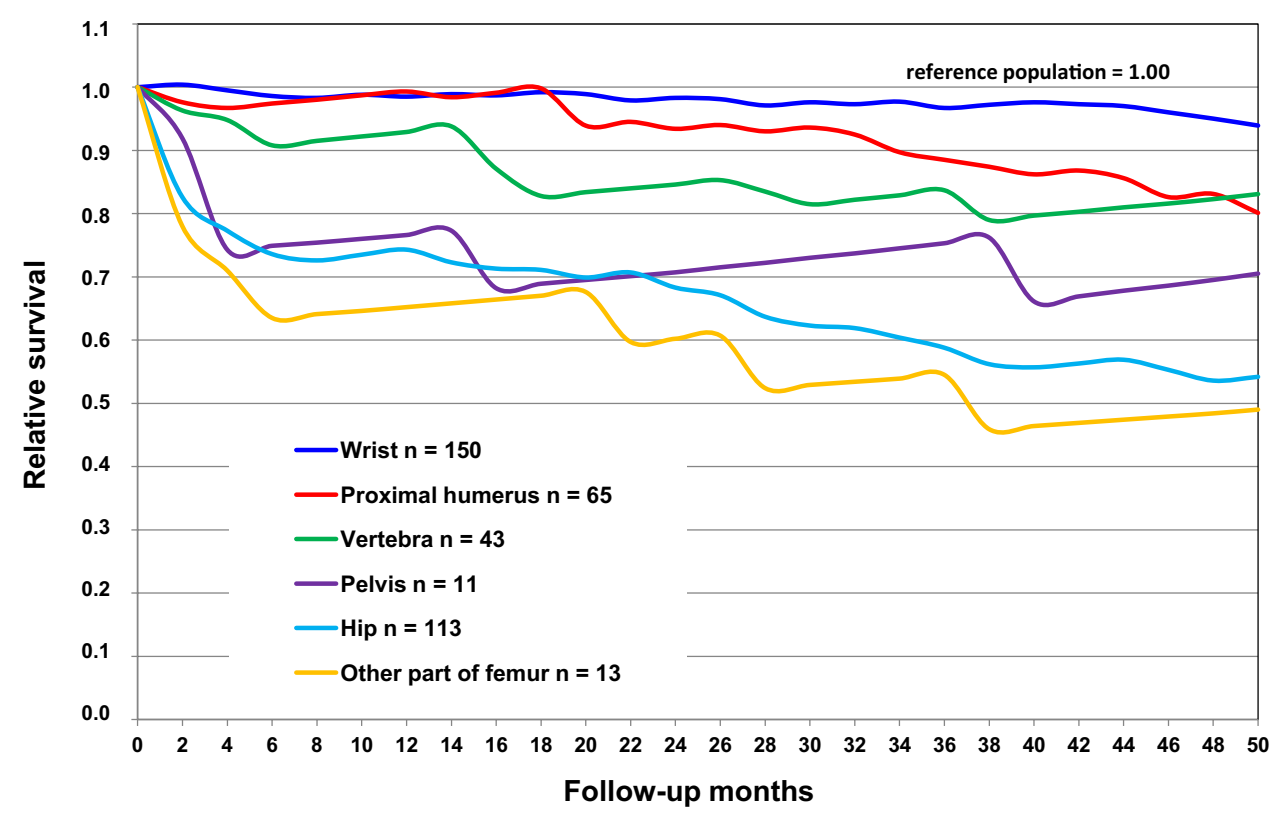

anti-osteoporotic medication. According to the Finnish Current Hip Fracture Care Guidelines, anti-osteoporotic treatment should only be considered if the patient would rehabilitate to independent mobility [20]. A recent Finnish hip fracture study among 538 home-dwelling patients showed that $9 \%$ of the patients were in permanent institutional care 12 months after the index fracture [29].

Moreover, in our present data the use of anti-osteoporotic treatment among patients who were alive 12 months after the index fracture was $63 \%$ in those with clinical vertebral fracture, $36 \%$ in those with proximal humerus fracture, and $24 \%$ in those with wrist fracture. Of all patients, $62 \%$ used calcium plus vitamin D supplements daily (at least $800 \mathrm{IU}$ vitamin $\mathrm{D}$ per day).

Post-fracture use of anti-osteoporotic medication in our data was not optimal. The main reason was a long-lasting public discussion on overdiagnosing bone fragility and overtreating osteoporosis in various Finnish media sources during the study year 2015. These arguments have also been published in 2015 [30]. All this had a potential to discourage patients with low-energy fractures undergoing fracture preventive measures and anti-osteoporotic treatment. Moreover, many patients in Finland quit their anti-osteoporotic medication.

A recent study from Denmark, Catalonia and the UK in 2005-2015 showed a remarkable treatment gap in antiosteoporotic medication among elderly patients with a first osteoporotic index-fracture: in Denmark 88-90\%, in Catalonia $80-88 \%$ and in the UK $63-73 \%$ were not treated with anti-osteoporotic medication [31].

In our previous study (2003-2004), the mean S-25OHD concentration was $38.1 \mathrm{nmol} / \mathrm{L}$ among female and
$37.0 \mathrm{nmol} / \mathrm{L}$ among male hip fracture patients [32]. In the present study, the mean concentration in both sexes was 2.5 times higher than 11 years ago, and among 113 hip fracture patients the mean S-25OHD concentration was $94.5 \mathrm{nmol} / \mathrm{L}$ (SD 34.7). This indicates that vitamin D deficiency among the elderly is not as common as it was in Finland 11 years ago. This result is supported by a recent prospective study using national data on Finnish adults aged $\geq 30$ years with an 11-year follow-up [33]. The mean S-25OHD level among those aged $\geq 75$ years-old increased from $43 \mathrm{nmol} / \mathrm{L}$ in 2000 to $65 \mathrm{nmol} / \mathrm{L}$ in 2011, and the prevalence of vitamin D deficiency decreased from 65.5 to $9.7 \%$ during the same time period [33].

Our study showed a higher long-term survival rate among patients with a sufficient (50-74 nmol/L) and optimal S-25OHD level (75-119 nmol/L). Many studies have shown that a low concentration of S-25OHD is associated with increased risk of death from all causes. A European meta-analysis of eight prospective studies with 26916 study participants (median age 61.6 years) and a median S-25OHD concentration of $53.8 \mathrm{nmol} / \mathrm{L}$, showed that participants with a concentration of 75-99 $\mathrm{nmol} / \mathrm{L}$ had the lowest all-cause mortality. Low S-25OHD level was significantly associated with all-cause mortality and cardiovascular mortality [34]. The median follow-up time was 10.5 years [34].

A nationwide register-based study from Denmark reported that hip fractures were associated with the highest excess mortality (33\% in men and $20 \%$ in women at 1 year after fracture). One-year excess mortality after fracture of the femur or pelvis was 20-25\%; after vertebral fractures $10 \%$; after humerus, rib, or clavicle fractures 5-10\%; and 
after lower leg fractures 3\% [35]. In the present study, the highest excess mortality at 1 year was among female patients with femoral shaft or distal femur fracture (44\%), and among male hip fracture patients (44\%), followed by male vertebral fracture patients (26\%), and by female hip fracture patients $(22 \%)$.

The mortality of hip fracture patients in the present study was high at 4 months and 1 year: $25 \%$ and $31 \%$, respectively. Patients' standard geriatric rehabilitation was not optimal. In the study-year (2015), 114 hip fracture patients (not included in the present data) living in South-Kymenlaakso were operated on the central hospital in the city of Kotka. They received post-operative multi-disciplinary rehabilitation at the Hoiku Rehabilitation Center. Their mortality at 4 months and 1 year was $15 \%$ and $19 \%$, respectively. A recent metaanalysis on one-year mortality rate post hip fracture suggested $22 \%$ to be an expected mortality rate [36].

Some results of the present study were published in Finnish language in November 2017 [37]. Quite soon after publication, patients' waiting time to dental care in the study region remarkably shortened enabling to start antiosteoporotic medication as soon as possible. It is important to avoid any delay in starting the medication to decrease the risk of subsequent fractures [38]. Furthermore, since November 2019 all hip fracture patients in the city of Kouvola have received post-operative multidisciplinary rehabilitation at the above-mentioned Hoiku Rehabilitation Center. A systematic review and meta-analysis showed that in comparison to usual care, general or orthopedic geriatric rehabilitation programs improved patients' functional status and reduced their admissions to nursing homes and mortality [39].

\section{Strengths and limitations}

The strengths of our study were the long follow-up time, detailed patient-specific data, and the large number of consecutive patients at a single institution. We received a remarkably high response rate to the questionnaire (71\%, $374 / 525)$. Usually, lower response rates are reported for pencil and paper studies [40]. The high response rate showed that our FLS had succeeded quite well.

We are convinced that most of the low-energy injuries in the study area have been treated in the study hospital because it is the only acute care hospital in this region and all X-rays ordered by the primary health centers are performed at this hospital. Some of the injury cases may have been treated at local private clinics and are not included in these data. We believe that these cases are rare, because in Finland elderly injured patients are usually treated in the emergency departments of acute care hospitals.

Only native-born Finns were included in our data and no other ethnic groups were represented. The foreign-born population in Finland is small (6\%) and less than 3\% of foreign-born persons lived in the study area in 2015 (Statistics Finland). The ethnicity, race, and different cultural background of foreign-born individuals may influence the prevalence of low-energy fractures. In Sweden [41] and Norway [42], for example, there was a reduced risk of hip fracture in foreignborn individuals.

Our study has several limitations. It is a single-center study, and therefore, the results cannot be generalized to a larger population. There was no control group without fracture liaison services, either. Moreover, the long-term use of anti-osteoporotic treatment was not evaluated. Gathering data from other centers would make the results more reliable. However, our study city was the 10th largest city in Finland (a country with 5.5 million inhabitants) in 2015.

\section{Conclusions}

About $75 \%$ of all patients belonged to MOF category. Previous fractures were sustained by nearly half of all patients, of whom more than one in three patients had two to five previous fractures. Our minimal FLS resource increased the catchment of low-energy fracture patients and the FLS also was inexpensive. The total direct costs for FLS in the study year were only $1.3 \%$ of the annual total costs of all low-energy fractures in the study area. Hip fracture patients need multidisciplinary rehabilitation for optimal recovery to minimize the post-operative mortality during the first year after the index fracture. In total, anti-osteoporotic medication was started in $38 \%$ of patients. This was not optimal considering the main goal of FLS, which is to reduce fracture risk and subsequent fractures. Differences in mortality between sexes were found at 4 years. Mortality was significantly higher among men than women in proximal humerus fractures and in hip fractures. The excess mortality during the first four-year post-fracture follow-up time was highest among patients with femoral fractures.

Supplementary Information The online version contains supplementary material available at https://doi.org/10.1007/s40520-021-01826-x.

Acknowledgements This work was supported by the Research Foundation of Helsinki University Hospital. The sponsor had no role in study design; in the collection, analysis and interpretation of data; in the writing of the report; or in the decision to submit the article for publication.

\section{Declarations}

\section{Conflict of interest None.}

Statement of human and animal rights This study was performed in line with the principles of the Declaration of Helsinki. Approval was granted by the head of Kouvola Health Care District (diary number 7649/05.17.00/2015).

Informed consent For this type of study, no informed consent is required. 
Open Access This article is licensed under a Creative Commons Attribution 4.0 International License, which permits use, sharing, adaptation, distribution and reproduction in any medium or format, as long as you give appropriate credit to the original author(s) and the source, provide a link to the Creative Commons licence, and indicate if changes were made. The images or other third party material in this article are included in the article's Creative Commons licence, unless indicated otherwise in a credit line to the material. If material is not included in the article's Creative Commons licence and your intended use is not permitted by statutory regulation or exceeds the permitted use, you will need to obtain permission directly from the copyright holder. To view a copy of this licence, visit http://creativecommons.org/licenses/by/4.0/.

\section{References}

1. Melton LJ, Atkinson EJ, O'Connor MK et al (1998) Bone density and fracture risk in men. J Bone Miner Res 13:1915-1923. https:// doi.org/10.1359/jbmr.1998.13.12.1915

2. Black DM, Ropsen CJ (2016) Postmenopausal osteoporosis. N Engl J Med 374:254-262. https://doi.org/10.1056/NEJMcp1513 724

3. Reito A, Kuoppala M, Pajulampi H et al (2019) Mortality and comorbidity after non-operatively managed, low-energy pelvic fracture in patients over age 70: a comparison with an agematched femoral neck fracture cohort and general population. BMC Geriatr 19:315. https://doi.org/10.1186/s12877-019-1320-y

4. Åhman R, Siverhall PF, Snygg J et al (2018) Determinants of mortality after hip fracture surgery in Sweden: a registry-based retrospective cohort study. Sci Rep 8:15695. https://doi.org/10. 1038/s41598-018-33940-8

5. Egol KA, Koval KJ, Zuckerman JD (1997) Functional recovery following hip fracture in the elderly. J Orthop Trauma 11:594599. https://doi.org/10.1097/00005131-199711000-00009

6. Shah MR, Aharonoff GB, Wolinsky P et al (2001) Outcome after hip fracture in individuals ninety years of age and older. J OrthopTrauma 15:34-39. https://doi.org/10.1097/00005131200101000-00007

7. Weller I, Wai EK, Jaglal S et al (2005) The effect of hospital type and surgical delay on mortality after surgery for hip fracture. J Bone Joint Surg Br 87-B:361-366. https://doi.org/10.1302/0301620x.87b3.15300

8. Berry SD, Samelson EJ, Bordes M et al (2009) Survival of aged nursing home residents with hip fracture. J Gerontol A Biol Sci Med Sci 64:771-777. https://doi.org/10.1093/gerona/glp019

9. Ryg J, Rejnmark L, Overgaard S et al (2009) Hip fracture patients at risk of second hip fracture: a nationwide population-based cohort study of 169,145 cases during 1977-2001. J Bone Miner Res 24:1299-1307. https://doi.org/10.1359/jbmr.090207

10. Cosman F, de Beur SJ, Le Boff MS et al (2014) Clinician's guide to prevention and treatment of osteoporosis. Osteoporos Int 25:2359-2381. https://doi.org/10.1007/s00198-014-2794-2

11. Smith MG, Dunkow P, Lang DM (2004) Treatment of osteoporosis: missed opportunities in the hospital fracture clinic. Ann R Coll Surg Engl 86:344-346. https://doi.org/10.1308/1478708043 71

12. Vaile J, Sullivan L, Bennett C et al (2007) First fracture project: addressing the osteoporosis care gap. Intern Med J 37:717-720. https://doi.org/10.1111/j.1445-5994.2007.01496.x

13. McLellan AR, Gallacher SJ, Fraser M et al (2003) The fracture liaison service: success of a program for the evaluation and management of patients with osteoporotic fracture. Osteoporos Int 14:1028-1034. https://doi.org/10.1007/s00198-003-1507-z
14. Boudou L, Gerbay B, Chopin F et al (2011) Management of osteoporosis in fracture liaison service associated with long-term adherence to treatment. Osteoporos Int 22:2099-2106. https://doi. org/10.1007/s00198-011-1638-6

15. Marsh D, Åkesson K, Beaton DE et al (2011) Coordinatorbased systems for secondary prevention in fragility fracture patients. Osteoporos Int 22:2051-2065. https://doi.org/10.1007/ s00198-011-1642-x

16. McLellan AR, Wolowacz SE, Zimovetz EA et al (2011) Fracture liaison services for the evaluation and management of patients with osteoporotic fracture: a cost-effectiveness evaluation based on data collected over 8 years of service provision. Osteoporos Int 22:2083-2098. https://doi.org/10.1007/s00198-011-1534-0

17. Nakayama A, Major G, Holliday E et al (2016) Evidence of effectiveness of a fracture liaison service to reduce the re-fracture rate. Osteoporos Int 27:873-879. https://doi.org/10.1007/ s00198-015-3443-0

18. Working Group Appointed by the Finnish Medical Society Duodecim and the Finnish Endocrine Society and the Finnish Gynaecological Association (2018) Osteoporosis. Current care guideline. https://www.kaypahoito.fi. Accessed 1 Oct 2019

19. Kröger H (2013) FRAX fracture risk calculator in the diagnostics and treatment of osteoporosis. Duodecim 129:1149-1152 (in Finnish, English summary)

20. Working group appointed by the Finnish Medical Society Duodecim and the Finnish Orthopaedic Association (2017) Hip fracture. Current care guideline and summary. Accessed 2 May 2020 https://www.kaypahoito.fi/en/ccs00092

21. Nurmi-Lüthje I, Lüthje P, Kaukonen JP et al (2015) Positive effects of a sufficient pre-fracture serum vitamin D level on the long-term survival of hip fracture patients in Finland: a minimum 11-year follow-up. Drugs Aging 32:477-486. https://doi.org/10. 1007/s40266-015-0267-8

22. Hakulinen T (1977) On long-term relative survival rates. J Chron Dis 30:431-443. https://doi.org/10.1016/0021-9681(77)90036-4

23. Singer A, Exuzides A, Spangler L et al (2015) Burden of illness for osteoporotic fractures compared with other serious diseases among postmenopausal women in the United States. Mayo Clin Proc 90:53-62. https://doi.org/10.1016/j.mayocp.2014.09.011

24. Finnish Hip Fracture Database of the PERFECT (PERFormance, Effectiveness, and Costs of Treatment episodes) 2013. Available online: http://www.thl.fi/fi_FI/web/fi/tutkimus/hankkeet/perfect/ lonkkamurtuma/perusraportit

25. Svedbom A, Hernlund E, Ivergård M, EU Review Panel of IOF (2013) Osteoporosis in the European Union: a compendium of country-specific reports. Arch Osteoporos 8:137. https://doi.org/ 10.1007/s11657-013-0137-0

26. Banefelt J, Åkesson KE, Spångéus A et al (2019) Risk of imminent fracture following a previous fracture in a Swedish database study. Osteoporos Int 30:601-609

27. van Geel TACM, van Helden S, Geusens PP et al (2009) Clinical subsequent fractures cluster in time after first fractures. Ann Rheum Dis 68:99-102. https://doi.org/10.1136/ard.2008.092775

28. Balasubramanian A, Zhang J, Chen L et al (2016) High risk of second fracture within $1,2,5$ years after prior fracture among women 65 years or older. J Bone Miner Res 31:S93 (Abstract FR02033)

29. Lahtinen A, Leppilahti J, Vähänikkilä H et al (2020) No major differences in recovery after hip fracture between home-dwelling female and male patients. Scand J Surg 109:250-264. https://doi. org/10.1177/1457496919847932

30. Järvinen TLN, Michaëlsson KM, Jokihaara J et al (2015) Overdiagnosis of bone fragility in the quest to prevent hip fracture. BMJ 350:h2088. https://doi.org/10.1136/bmj.h2088 
31. Skjødt MK, Khalid S, Ernst M et al (2020) Secular trends in the initiation of therapy in secondary fracture prevention in Europe: a multi-national cohort study including data from Denmark, Catalonia, and the United Kingdom. Osteoporos Int 31:1535-1544. https://doi.org/10.1007/s00198-020-05358-4

32. Nurmi I, Kaukonen JP, Lüthje P et al (2005) Half of the patients with an acute hip fracture suffer from hypovitaminosis D: a prospective study in southeastern Finland. Osteoporos Int 16:2018 2024. https://doi.org/10.1007/s00198-005-1987-0

33. Jääskeläinen T, Itkonen ST, Lundqvist A et al (2017) The positive impact of general vitamin D food fortification policy on vitamin $\mathrm{D}$ status in a representative adult Finnish population: evidence from an 11-y follow-up based on standardized 25-hydroxyvitamin D data. Am J Clin Nutr 105:1512-1520. https://doi.org/10.3945/ ajcn.116.151415

34. Gaksch M, Jorde R, Grimnes G et al (2017) Vitamin D and mortality: individual participant data meta-analysis of standardized 25- hydroxyvitamin D in 26916 individuals from a European consortium. PLoS ONE. https://doi.org/10.1371/journal.pone.01707 91

35. Tran T, Bliuc D, Hansen L et al (2018) Persistence of excess mortality following individual nonhip fractures: a relative survival analysis. J Clin Endocrinol Metab 103:3205-3214. https://doi. org/10.1210/jc.2017-02656

36. Downey C, Kelly M, Quinlan JF (2019) Changing trends in the mortality rate at 1-year post hip fracture-a systematic review. World J Orthop 10:166-175. https://doi.org/10.5312/wjo.v10.i3. 166

37. Lüthje P, Nurmi-Lüthje I, Pigg S, et al. (2017) Secondary fracture prevention in the city of Kouvola, Finland in 2015. Suomen
Lääkäril 45: 2606-2612 (in Finnish, English summary) www. laakarilehti.fi/english

38. Wang CU, Fu SH, Yang RS et al (2020) Timing of anti-osteoporosis medications initiation after a hip fracture affects the risk of subsequent fracture: a nationwide cohort study. Bone 138:115452. https://doi.org/10.1016/j.bone.2020.115452

39. Bachmann $S$, Finger $C$, Huss A et al (2010) Inpatient rehabilitation specifically designed for geriatric patients: systematic review and meta-analysis of randomised controlled trials. BMJ 340:c1718. https://doi.org/10.1136/bmj.c1718

40. Ebert JF, Huibers L, Christensen B et al (2018) Paper or webbased questionnaire invitations as a method for data collection: cross-sectional comparative study of differences in response rate, completeness of data, and financial cost. J Med Internet Res 20:e24. https://doi.org/10.2196/jmir.835

41. Albin B, Hjelm K, Elmståhl S (2010) Lower prevalence of hip fractures in foreign-born individuals than in Swedish-born individuals during the period 1987-1999. BMC Musculoskelet Disord 11:203. https://doi.org/10.1186/1471-2474-11-203

42. Aamodt G, Renolen R, Omsland TK et al (2020) Ethnic differences in risk of hip fracture in Norway: a NOREPOS study. Osteoporos Int 31:1587-1592. https://doi.org/10.1007/ s00198-020-05390-4

Publisher's Note Springer Nature remains neutral with regard to jurisdictional claims in published maps and institutional affiliations. 